$62^{\text {nd }}$ International Congress and Annual Meeting of the Society for Medicinal Plant and Natural Product Research - GA2014

\title{
Antimicrobial and antioxidant properties of propolis ethanol extracts from Terceira Island (Azores, Portugal)
}

\author{
Tiago Lourenço', Tânia Oliveira', Ana Margarida Ferreira², Rui Oliveira'1,4, Fátima Bento³, Dulce Geraldo³, \\ Cristina Almeida Aguiar ${ }^{1,4}$ e Ana Cunha ${ }^{1,4}$
}

\author{
1Department of Biology, University of Minho \\ 2 Department of Chemistry, University de Trás-os-Montes e Alto Douro \\ ${ }^{3}$ Chemistry Centre, Department of Chemistry, University of Minho \\ ${ }^{4} \mathrm{CITAB}$ - Centre for the Research and Technology of Agro-Environmental and Biological Sciences, Department of \\ Biology, University of Minho
}

Bees produce a resinous mixture named propolis known to have several functions in the beehive, namely structural and sanitary [1,2]. Propolis presents a rich and complex chemical composition, imparted from the several plant materials collected, and several compounds and extracts have been associated with biological activities of high interest ${ }^{[3]}$.

This study focuses on the antimicrobial activity and antioxidant capacity of ethanolic extracts (EE) obtained from propolis samples collected in 2010, in five different areas of the Terceira Island (Azores Archipelago).

Antimicrobial activity was evaluated by dilution assay incorporating different EE concentrations in solid media. Bacteria and yeasts of clinical and agrofood relevance were used as indicators of susceptibility. The results showed that Gram-positive bacteria displayed more resistance (best MIC value $200 \mu \mathrm{g} / \mathrm{ml}$ ) than the Gram-negative $(100 \mu \mathrm{g} / \mathrm{ml})$. Extracts with higher antibacterial activity (e.g. EE4 and EE5) were generally distinct from those with greater activity against yeast (EE1), but species-specific susceptibilities and extract-specific efficacies against particular microorganisms were also observed, only EE1 was effective against $S$. epidermidis. A relationship between propolis macroscopic characteristics (colour, hardness and odour) and its antifungal activity was noticed. If confirmed for a broader range of samples, this relationship may constitute an important diagnostic tool.

The antioxidant capacity was assessed using cyclic voltammetry [4]. EE4 and EE5 showed the highest antioxidant capacities (39.6 and $23.5 \mathrm{mM}$ eq. gallic acid, respectively), in agreement with results from the antimicrobial assays. Chemical characterization of all EE are underway.

Despite being collected in a somewhat confined geographic area propolis samples exhibited diverse antimicrobial activities with different efficiencies and antioxidant capacities.

[1] - Fokt H., Pereira A., Ferreira A.M., Cunha A. and Aguiar C. How do bees prevent hive infections? The antimicrobial properties of propolis In: Current Research, Technology and Education Topics in Applied Microbiology and Microbial Biotechnology. A. Mendéz-Vilas (Ed.), pp. 481-493 (2010).

[2] - Falcão SI, Vilas-Boas M., Estevinho L.M., Barros C., Domingues M.R.M and Cardoso S.M. (2010) Phenolic characterization of Northeast Portuguese propolis: usual and unusual compounds. Anal Bioanal Chem 396: 887-897.

[3]- Thirugnanasampandan R et al. (2012) Asian Pacific Journal of Tropical Biomedicine 651-654.

[4] - Chevion S.,Roberts M. and Chevion M. (2000) The use of cyclic voltammetry for the evaluation of antioxidant capacity. Free Radical Biology \& Medicine 28(6): 860-870,.

This work is supported by national funds by FCT - Portuguese Foundation for Science and Technology, under the project PEst-OE/AGR/UI4033/2014. 